\title{
Harmony, Productivity, and Informed Decision Making: The Fundamental Competencies of the Chief Emotional Officer
}

\author{
Christopher Lowea, Julia Evans ${ }^{b}$
}

\begin{abstract}
Existing in most family firms, the chief emotional officer (CEmO) is the enigmatic heart of the organisation, linking family harmony with business performance and productivity. The literature is rich in acknowledging the existence and value of the CEmO in family firms, but little is said of the abilities mastered by CEmOs and how organisations can leverage the value of the CEmO through professional development. It is this nexus that this paper aims to fill. Commencing with an exploration of the literature on the purpose and value of the CEmO, key findings are advanced through interviews and a focus group. The specific site of research selected is one rich in family business in which to explore the CEmO phenomenon-the bus and coach industry in Victoria, Australia. Revealed is the fundamental competencies of the CEmO, being their adept ability to facilitate harmony, drive productive and focus values-based decision making in family firms. The outcomes that these competencies achieve and the obstacles and challenges of the $\mathrm{CEmO}$ role are also presented. Concluding remarks ask how the CEmO and these core competencies can be developed in a role that is often unstructured, intuitive, and unrecognised within the firm.
\end{abstract}

\section{Keywords}

Chief emotional officer (CEm0), family business, business sustainability, competency, professional development

The chief emotional officer $(\mathrm{CEmO})$ is the enigmatic heart that exists in family firms. They are the individual who is the steward of the family legacy, the keeper of "family" in the business; they are the one who instils a "sense of purpose, responsibility and community, and who embodies a spirit of cooperation and unconditional support" (Poza and Messer 2001: 33).

The CEmO is often assumed to be a woman, the spouse of the founder or chief executive officer (CEO). Their prime function is to facilitate communication and positive relationships, foster harmony within the family and the business, and lead informed decision making during times of transition. In doing so, CEmOs leverage and master emotional intelligence
(EI) in ways that are highly valuable to the business. Nevertheless, negotiating the family dynamic and managing confidentiality, trust, openness, and attitudes toward EI (especially in predominately male-orientated workplaces) present challenges to the existence and acceptance of the CEmO. However, little else is known about the $\mathrm{CEmO}$ in family business, other than the role they play, the value they

aMonash Sustainability Institute, Australia

bIndependent scholar, Australia

\section{Correspondent Author:}

Christopher Lowe, 450 Graham Street, Port Melbourne, VIC 3207, Australia

E-mail: clowe@busvic.asn.au 
add to the family working together and identifying the challenges.

In exploring the literature, Sorenson, Goodpaster, Hedberg, and Yu's (2009) work on the "family point of view" is drawn on to form a lens to view the CEmO. Their work provides a useful framework-a governance model unique to family businesses - in which collaborative dialogue helps to shape the family's shared moral compass, which in turn provides a framework of expectations and obligations (Sorenson et al. 2009). This paper proposes that the family business's CEmO is central to the "family point of view", significantly influencing how family firms function.

The little literature available generally acknowledges the existence of the role in family businesses - a role that is often unstructured, intuitive, and unrecognised within the business. In acknowledging the existence of the CEmO, their impact and value are recognised. Yet, little is said of the fundamental capabilities that CEmOs master and how organisations can leverage the value of the $\mathrm{CEmO}$ through professional development. It is this nexus that this paper aims to fill.

While this paper contributes to further understanding the role, responsibilities, and value of the CEmO, and how they affect family-owned and operated businesses, it explores the uncharted area of identifying capabilities and their development. Specifically, this paper asks: What are the fundamental competencies of the $\mathrm{CEmO}$ and how can they be developed in a role that is highly intrinsic and rarely formalised?

Research was conducted by way of interviews with specialists in the fields of EI, family business, and diversity in multi-national organisations. Key findings and their views where then shared in a focus group with business owners, senior managers, and employees - predominately women - from family, and non-family businesses within the bus and coach industry in Victoria, Australia.
The decision to position the research in this setting was based on the accelerated consolidation and unprecedented transition of family-owned and operated businesses in the Victorian bus and coach industry. Bus operators' sense of urgency to "get big or get out" appears to run counter to community and regional development endeavours attempting to foster and sustain small business as the "engine room of our economy" (Coalition Party 2013: 3), particularly in regional and rural areas. In light of this tension, the setting for the research provided a current, relevant landscape in which to understand the abilities the $\mathrm{CEmO}$ masters and leverages in promoting the "family point of view", family harmony, and business productivity in times of acute decision making.

This study centres on the $\mathrm{CEmO}$ in family businesses and advances our understanding of the $\mathrm{CEmO}$ beyond the current commentary on their role and value. This paper presents the discovery of three foundation competencies that $\mathrm{CEmOs}$ master and outlines preliminary evidence that CEmOs exist in non-family firms, indicating that the ability to facilitate harmony, drive productivity, and informed decision making are highly valued in all organisations. Specifically, this paper asserts that the role of CEmO in family businesses is central to developing the "family point of view". This paper will be of interest to those in the field of entrepreneurialism and business studies focused on family business sustainability and governance models, succession planning and business transition and additional disciplines, such as EI and leadership, women in business and professional development, and business education.

\section{THE “FAMILY POINT OF VIEW"}

In advancing a greater understanding of the CEmO, Sorenson et al.'s (2009) work on the "family point of view" is drawn on in this paper. Their work examines business governance systems and how they are used to identify and develop assets that benefit the family's 
objectives, the business itself, and individuals. They suggest that good governance of both the business and the family requires family members to develop a shared point of view about the business and their involvement with it - that is, the "family point of view".

Sorenson et al.'s (2009) empirical analyses confirm that a positive relationship exists between collaborative dialogue and ethical norms, ethical norms and family social capital, and family social capital and firm performance. The "family point of view" is the united family perspective, achieved through collaborative dialogue and shared ethical norms. Here, collaborative dialogue helps shape the family's shared moral compass, which, in turn, provides a framework of expectations and obligations: Business gives priority to values that promote reliable performance, fulfil customer expectations, and produce positive financial returns (Sorenson 2013: 117).

As communication is the primary mechanism for establishing and maintaining moral beliefs (Hoffman, Hoelscher, and Sorenson 2006), Sorenson et al. (2009) theorise that "collaborative dialogue, one form of communication, will be positively related to an emphasis on ethical norms within a family firm" (Sorenson et al. 2009: 240). When families establish a business, beliefs and norms prominent in the family tend to carry over to the business. This inheritance or passing on of beliefs and norms is one of the characteristics that make family companies distinctive (Sorenson et al. 2009).

Sorenson (1999) found that extensive collaboration within the family was associated with increased resources available to the family business, including loyal customers, family support, and community goodwill. The use of resources from the business enables the business to benefit from the assets and capabilities fostered within the family. Family members who understand and participate in the governance of the enterprise can work with the business to prepare other family members to be potential employees, leaders, board members, active shareholders, community representatives, and participants in family foundations and philanthropy. In turn, being highly resourced delivers "positive family social capital" (Sorenson et al. 2009: 242) founded on positive network relationships among the family, employees, customers, and community members. This implies that "an emphasis on ethical norms helps to build enduring network relationships" (Sorenson et al. 2009: 250). The "family point of view" is useful in providing a lens to further understand family-business sustainability, values, culture, and norms, how decisions are made and what they are based on, and how family values become business values (Sorenson 2013).

This paper asserts that the CEmO is central to facilitating collaborative dialogue to develop (and maintain) the family's common moral compass. They are a resource who considers family and business situations from an emotional perspective. They are the person who is central to, albeit discrete in, preparing the family in a harmonious and productive way, for whatever the business wishes to achieve. They are the individual who often translates, shares, and upholds obligations and expectations, with the aim of ensuring that "the family point of view" is evident in business operations, consumer, and stakeholder interactions, and engagement. In doing this, the CEmO is aptly placed to influence why and how transition will occur, or at the very least, to provide the business with a competitive advantage that bolsters sustainability. As Pritchard came to realise: (W)ith the help of our $\mathrm{CEmO}$, there were structures, rituals in place to help us utilise our unique situations to build a stronger family and business dynamic (Pritchard 2011: 181).

In respect of non-family corporations and multinational organisations, a possible theoretical basis for the CEmO could be stakeholder theory-or, more specifically, the "stakeholder perspective". Stakeholder theory intertwines organisational 
management and business ethics to address morals and values in managing an organisation. Detailed by Freeman (1994), the theory attempts to address the "principle of who or what really counts" (Freeman 1994: 411) in terms of the firm's performance, including governmental bodies, political groups, trade associations, trade unions, communities, financiers, suppliers, employees, customers and sometimes even competitors (because of their capacity to affect the company's performance). The "stakeholder perspective" offers insights into predicting the extent to which organisations undertake some level of social performance to achieve social legitimacy, and have a place in framing, organising, and guiding corporate social responsibility systems and programmes. However, the focus for this paper is family businesses; an exploration of the CEmO in non-family companies through the "stakeholder perspective" is for investigation at another time.

With this perspective in place, the paper now turns to a review of the literature on the CEmO.

\section{WHAT THE LITERATURE TELL US OF THE CEmO}

Relatively little is known about the role of the CEmO and there is no universally embraced definition or consideration of other characteristics of the CEmO, including gender, relationship to the family, and existence in corporates, multinational and not-for-profit organisations. Nevertheless, some literature attempts to define who the $\mathrm{CEmO}$ is and what they do. In Pritchard's (2011) reflection on her own family business, she clearly identifies her mother as the CEmO. Inspired by Poza and Messer's (2001) work on the "chief trust officer", Pritchard views the $\mathrm{CEmO}$ as the steward of the family legacy, the keeper of "family" in the business, and the individual who instils a "sense of purpose, responsibility and community, and embodies a spirit of cooperation and unconditional support" (Poza and Messer 2001: 33).
As there is no official definition of "family business" in Australia (Australian Bureau of Statistics 2013), for the purposes of this paper, Family Business Australia's (2013) definition has been adopted: A family business is comprised of two or more members of the same family involved in the business with one or more related members having a controlling interest (Family Business Australia 2013: 27).

A review of the literature points to the core functions of the CEmO: mediator of harmony within the family and the business, a high-performing interpreter and communicator, and upholder of what it means to be "family". The CEmO is often portrayed as the "glue" that keeps the family together and the business aligned with its priorities:

(CEmOs) provide emotional support, smooth things over and keep communication open... (They) help acculturate in-laws, protect family traditions and values, and make sure the family gets together to socialize and have fun... (They are) the glue that holds the family and the business together through tough times. (Lyons and Rivers 2008: 1)

(CEmOs are) healers, mediators, facilitators, and communication conduits for their families. They are the fence menders in business and family relationships. Individuals performing this role have been referred to as "trust catalysts". (LaChapelle and Barnes 1998; Poza and Messer 2001: 30)

CEmOs were found to improve others' understanding of each other by "interpreting the behaviour of one family member for another" (Jimenez 2009: 55), thereby fostering harmony among family members in the business as well as those not connected to it. The $\mathrm{CEmO}$ will "often have a unique appreciation of the interpersonal and developmental challenges in family business continuity" (Poza and Messer 2001: 30) and possibly have some suggestions and solutions in mind.

CEmOs were also identified as being perceptive communicators. Utilising their exceptional listening skills, they can appropriately approach and easily adapt to every situation in a highly customised way 
(Mayer 2008). In addition, they uphold expectations that communication remains open, direct, and respectful (Wolper 2012). The CEmO's appreciation of the family dynamic coupled with their exceptional communication skills means that they are frequently able to broaden the dialogue from an exclusive focus on facts to a broader view encompassing both facts and feelings, where better decisions can be made... (They are) often effective at putting succession planning and transition to retirement on a family's agenda (Poza and Messer 2001: 30).

Such dialogue would be collaborative, facilitated adeptly by the $\mathrm{CEmO}$, and result in a deeper understanding of the "family point of view". Sorenson et al. (2009: 241) expect that families who "promote addressing family concerns, openness, participation, and collaboration will yield shared moral beliefs and support for ethical norms". The CEmO is central to achieving this outcome in family businesses.

The literature suggests that the CEmO is a phenomenon more commonly found in family businesses than non-family businesses. The CEmO is usually assumed to be the wife or partner of the business's CEO or founder; as such, they are highly motivated to create an environment in which family and business can co-exist harmoniously (Pritchard 2011). Although family business research has largely ignored the role of the CEO's spouse (Poza and Messer 2001: 25), some research has revealed that this individual operates in two worlds: acting as business advisor or consultant in addition to her role as wife (Gillis-Donovan and Moynihan-Bradt 1990), all the while remaining in the background. Another study showed that CEO spouses assume different leadership functions depending on their relationship to the CEO, their knowledge, and interest in the business, and their commitment to a vision that includes continuity of the business in family members' hands (Poza and Messer 2001: 28).

In identifying 10 megatrends in family business in 1998, Aronoff claimed that women's roles in family business continue to expand, in that "the widow who becomes chairperson, the supportive wife who keeps the books, the behind-the-scenes 'CemOs' are all stereotypical women's roles in family business" (Aronoff 1998: 184). It is also noted that family businesses under the leadership of "CEO spouse as widow" tend to deteriorate when the spouse dies: (W)hen "Mom" dies, the company is hobbled, even more so than when the founder passes on. Sibling rivalries may intensify. Key decisions lag. The business loses its family feeling (Sorenson and Ward 1989: 40).

The literature implies that the CEO spouse and the $\mathrm{CEmO}$ are one and the same, as this illustrates: (The CEO spouse has the) unique yet usual role as steward of the family legacy, facilitator of communications, and touchstone of EI in family relations. CEO spouses often play a determining role in successful generational transitions, but not without tensions and dilemmas to resolve (Poza and Messer 2001: 25).

However, without a universally accepted definition of the CEmO in family business, this is difficult to determine any distinctions between the $\mathrm{CEmO}$ and the role and influence of the CEO spouse.

The existence of a CEmO in a family business represents an acknowledgement that the emotional health of a business is just as important as its financial health (Mayer 2008: 30). This idea is advanced by commentary suggesting that successful family businesses do not attempt to remove the emotional power of family relationships from within the business (Wolper 2012), but instead to leverage them. Leveraging and leading emotions in business is embedded in EI, which is "the ability to monitor one's own and others' feelings and emotions, to discriminate among them and to use this information to guide one's thinking and actions" (Mayer and Salovey 1989: 189). This is where the CEmO comes to the fore: (The $\mathrm{CEmO}$ is) an important promoter in stimulating EI and enhancing the EI leadership in the family business (Meng-Yun, Yan, and Wen 2010: 565). 
While the title "CEmO" may be slightly flippant, the seriousness of the role highlights the need for symbolic and actual business managers to possess a good degree of EI in order to be skillful leaders. After all, EI represents two thirds of the success of business leaders (Conley 2011).

Promoting EI within the family and business is one thing, but upholding what it means to be a family is another. It is suggested that the CEmO's role also includes protecting and promoting family culture and values (Meng-Yun et al. 2010), and ensuring that family traditions and closeness are respected and preserved (Mayer 2008). CEmOs have the potential to enhance the respect and influence capital that they command in matters of great importance to the family and the business... (They are) the keepers of the sense of history and may even nurture a sense of love for the business (Poza and Messer 2001: 31).

Via this, the CEmO helps to rear children with a sense of the business and its customers, acknowledging that "They [the CEmOs] are role models for the next generation and builders of new legacies, legacies their preceding generation did not consider important" (Poza and Messer 2001: 32).

As overseers of the family legacy, CEmOs tend to be committed to preserving the family's "good" name (Lansberg 1995); this notion indicates that the identity and reputation of the business are intertwined with shared values and ethical conduct. Through the "family point of view" lens, a "good" name results in heightened, positive family social capital—an appealing advantage in times of transition. Overall, the CEmO instils a "sense of what the business stands for and what it means to the family" (Pozer and Messer 2001: 32 ), for the "family identity is made up of common family beliefs about the family, and how the family relates to the business and the community" (Sorenson 2013: 126). Through the "stakeholder perspective", a key concern for non-family CEmOs is ways in which employees of corporate and multinational engage with the business and the community.
The existing literature rarely considers the $\mathrm{CEmO}$ to be other than a female spouse entrenched in the family business and typically perceived as the highest ranking, the oldest woman in the business (Wolper 2012). However, the CEmO may not be a woman or a member of the immediate family. Instead, they may be someone who is the main confidante and supporter of the founder or current CEO because of their unique knowledge about the family and the business (Jimenez 2009: 55). The literature also fails to explore the existence of CEmOs in non-family businesses, such as corporate, multinational, and not-for-profit organisations.

In spite of offering a universally embraced definition of $\mathrm{CEmO}$, the literature acknowledges the existence of the $\mathrm{CEmO}$ in family business (in the main, as the spouse of the CEO or founder) and numerous attempts are made to articulate their role, value, and the outcomes they facilitate. This is where the literature ends. Other roles within the commonly referred to "C-Suite" [that is, CEO, Chief Financial Officer (CFO), Chief Information Officer (CIO), etc.] have clearly defined position purpose, functions, measures, and underpinning skills and abilities. It is the identification of foundation competencies for the $\mathrm{CEmO}$ that has informed the research question, as it may in turn help sharpen the purpose and functions of the role.

\section{METHODOLOGY}

\section{Qualitative Mixed-Methods Approach}

In addressing the research question-What are the fundamental competencies of the $\mathrm{CEmO}$ and how can they be developed in a role that is highly intrinsic and rarely formalised? A qualitative mixed-methods approach within the interpretive tradition was adopted, utilising a mix of conceptual analysis of the CEmO via the literature, interviews, and focus group. The interpretative research tradition demands a greater 
exploration into discovering patterns, areas of commonality, and uncovering explanations relating to the research question, to "decode, describe, analyse, and interpret accurately the meaning of a certain phenomena" (Fryer 1991).

The conceptual analysis consisted of viewing the $\mathrm{CEmO}$ outlined in the literature from the "family point of view". It allowed for a construction of the CEmO by way of interpreting the argued claims through a theoretical lens. The results of this analysis were outlined in the previous section.

Qualitative data obtained through the interviews and focus group provided rich descriptions, explanations, and unintended data that combined to form a construction of meaning of the $\mathrm{CEmO}$ in the selected site of research. In November 2013, interviews with a specialist in the field of EI, a subject matter expert in family business and a senior manager in a multi-national transport organisation were conducted. The interviewees are Ms Erica Nelson, a psychologist and EI specialist, Mrs Philippa Taylor, the CEO of Family Business Australia in Australia, and Mrs Leah Waymark, the General Manager of Corporate Relations for a large multinational rail operator. The interviews were conducted in Melbourne, Australia, by a woman, and all three interviewees were women.

Prior to the interview, a copy of Pritchard's (2011) chapter "Putting family in family business: the role of the chief emotional officer" was provided to the interviewees to establish context. The recorded interviews asked the same questions of each interviewee: Do CEmOs exist? What results do CEmOs achieve? What core skills does a CEmO need to master, and why?

In November 2013 in Melbourne, Australia, a focus group was conducted. The group consisted of volunteers-business owners, senior managers, and employees from family and non-family businesses within the selected site of research, a total of 63 participants with $90 \%$ of them are women. The focus group commenced with an overview of the $\mathrm{CEmO}$ (as seen through the lens of the "family point of view"), followed by Pritchard's (2011) reflections on family business. Working in smaller groups, participants were asked the same three questions as the interviewees. This allowed for extensive discussion on the CEmO's existence, abilities, influence, and challenges in a highly contextualised way. Responses were reported back and compared with the key findings and themes from the interviews. The three interviewees were then invited to participate in the focus group on an open forum on the topic, which discussed the following questions: Does a focus on emotions mean that we focus on gender-can men be CEmOs? What are the obstacles and challenges to the role? Should the role be formalised? How can we nurture and develop CEmO talent?

The interviews and focus group discussions were audio recorded, enabling the collection, summarisation, and analysis of responses.

\section{The Victorian Bus and Coach Industry}

The specific site of research selected is one rich in family business experiencing significant transition in which to explore the CEmO phenomenon - the bus and coach industry in Victoria, Australia.

The Victorian bus and coach industry is mature, significant, regulated, and represented. The industry consists of approximately 600 operators, most of whom are contracted to the state government to deliver metropolitan and regional, mainstream and special-school, regional intercity, rail-replacement and airport shuttle bus and coach services. With just over 5,000 buses in Victoria, the industry directly employs approximately 8,000 people (Currie and Delbosc 2009), with an additional 3,000 jobs in "flow-on effects" (National Institute of Economic and Industry Research 2010). In 2009, the industry was valued at $\$ 1.1$ billion, or $.4 \%$ of gross state product. The industry is regulated through mandatory legislation and represented by a voluntary professional association, the Bus Association Victoria Inc (BAV). 
At the time of writing, BAV membership consisted of $83 \%$ small operators (1-10 buses), $14 \%$ medium operators (11-100 buses), and 3\% large operators (100+ buses). Five percent of BAV operator members are metropolitan based, located mainly in the neighbourhood they are contracted to service. Victorian small bus operators (with less than 10 buses) declined by around 30\% during the period 2005-2013 . However, the number of large bus operators (with more than 100 buses) more than doubled in the same period. Other Australian state-based voluntary professional associations have reported similar trends in operator numbers.

Most operators are second-, third-, fourth-, and sometimes even fifth-generation operators, a feature common to the industry yet unique given the youth of enterprise in Australia. These operators anticipate long careers not just for themselves but for their offspring. As a result, they are careful to ensure that today's actions do not jeopardise longer-term prospects or that futuristic ambition does not rob the firm of resilience or sustainability. Family businesses in the industry tend to concentrate on preserving tradition and the status of the family in their community as a means to building their reputation and securing their future.

The decision to position the research in Victorian bus and coach industry was based on the accelerated consolidation and unprecedented transition of family-owned and operated businesses over recent years. Bus operators' sense of urgency to "get big or get out" appears to run counter to community and regional development endeavours attempting to foster and sustain small business as the "engine room of our economy" (Coalition Party 2013: 3), particularly in regional and rural areas.

Business consolidation (or cessation) is currently presenting itself as both a major opportunity for and a serious challenge to the bus industry, not just in Victoria, but Australia-wide. Preliminary findings from doctoral research establish several reasons for this:
(1) Increased legislation impacting bus operators and their operations, including mandatory professional development, ongoing business accreditation, and additional obligatory requirements colloquially referred to as "red tape";

(2) Family businesses seeing an increase in "offspring mobility". Here, the benefits of the family business are translated into the provision of tertiary education, access to global ideas, advancements in technology and best practice, and greater opportunities to travel and work. As a result, offspring mobility is often a key influencer in children choosing not to work or to continue working in the family business;

(3) Bus service cancellations, where rationalisation of regional school-bus services has occurred due to low or declining student numbers. Regional and rural family bus operators typically consist of a "mum and dad" operation.

In light of these tensions, the setting for the research provided a current and relevant landscape in which to understand the abilities the CEmO masters and leverages in promoting the "family point of view", family harmony, and business productivity in times of acute decision making.

\section{RESULTS}

An exploration of key findings from the interview and focus group questions and broader discussions follows, interwoven with commentary from the literature.

\section{CEmOs Do Exist and Have a Profound Role to Play}

The CEmO was found to exist in both family and non-family businesses alike. Centring the focus on family businesses, research participants perceived the $\mathrm{CEmO}$ role as a nexus between the harmony within the family and the productivity of the business. This link was succinctly made yet is rarely alluded to in the literature. It provides a platform on which the family can consider and work through strategic decisions. 
The ways in which the $\mathrm{CEmO}$ contributes to family harmony and business productivity rely on a complex, intricately woven mix of activities and abilities.

In defining what CEmOs do (what of their role), three core activities emerged:

(1) Guiding the family and business members through conflict by "putting things into context, reflecting on history and shared experiences" (interviewee response);

(2) Upholding and defending "the good"- that is, the values, norms, and traditions associated with the culture, operations, and reputation of the family business;

(3) Being a "sounding board", the "go-to" person and the "glue" that "holds everyone's emotions together, while being the person who somewhat silently drives improvement in the business's culture, leadership, people management, and employee satisfaction" (consolidated focus group responses).

The CEmO was found to effectively execute these activities (how of their role) by skillfully absorbing, translating, conciliating, interpreting, facilitating, and listening so as to "understand what's underneath the iceberg of a family member's emotions" (interviewee response).

Overall, the "what" and the "how" of the CEmO were considered to be "soft" skills, commonly known as interpersonal or social skills such as rapport building, relationship management, and influencing abilities (Reynolds 2005), the ability to motivate staff to work together to achieve a common objective and resolve conflicts that may arise (Cole 1999). Soft skills predominately focus on people, process, and community (Costin 2002) and are "necessary to enable one to articulate a vision; to enrol others in possibilities; and to communicate values, standards, and expectations" (HjYunus and Hassan 2012: 12). While "soft" in title, it was promptly emphasised that "tasks of this nature require CEmOs to possess and master the 'hardest' skills of all" (interviewee response). Sorenson et al.'s (2009) "family point of view" values these skills as a key asset throughout the business's entire journey, from collaborative dialogue to establishing ethical norms and resourcing the business's social capital and performance.

\section{Outcomes That CEmOs Achieve}

Research participants suggested that CEmOs (under their definition in the previous section) enable better, more contextualised outcomes, reduce conflict, and ensure fairness, have greater engagement with family, employees, customers, and business stakeholders, and facilitate improved communication. Here, the CEmO may concurrently embrace the "family point of view" and the "stakeholder perspective", with the latter focused on the "principle of who or what really counts" from a regulatory, political, industry, financial, employee, customer, community, and competitor perspective. It was suggested that these outcomes attributed to the role positively affect family cohesion and the business's productivity. The "family point of view" lens suggests that family businesses operating under these conditions are better able to leverage the company's social capital for performance. It was noted that this outcome would be the same when CEmOs operate in non-family businesses. However, it was noted that harmonious and productive family businesses may approach discussions about transition, consolidation, or cessation in a more strategic and objective way. The CEmO (here, positioned as a women) "creates calm and caring; symbolically, she stands for unity. In doing so, she fosters teamwork and communication" (Sorenson and Ward 1989: 40).

To summarise, CEmOs are best positioned to "navigate the heady mix of love, power, and money, and disparate personalities" (interviewee response). As a result, the $\mathrm{CEmO}$ becomes a champion for the process of professionalising the business, taking it from the "kitchen table to the board table (focus group response)"- a key requirement in the particular site of research in realising business potential in Victoria's current "get big or get out" environment. 


\section{The Obstacles and Challenges of the Role}

The CEmO role faces many challenges. The focus group identified six issues facing the $\mathrm{CEmO}$ as an individual and the $\mathrm{CEmO}$ as a concept.

First, the "gender agenda" assumes that the CEmO is the eldest woman (spouse or widow) within the family. Some recognised that the CEmO in their family business was in fact the male founder or retired CEO who left the "hard" business (that is, objective decision making and being result and task orientated) to the next-generation CEO. Such examples demonstrate that the CEmO's duties are not necessarily "women's business", and that all leaders and managers are able to develop their own CEmO abilities in order to be effective. It was also recognised - and the literature supports this - that the $\mathrm{CEmO}$ need not be a family member; instead, they may be an individual or advisor who has been intimate with the family's journey.

It was also suggested that an extension of the "gender agenda" is where family members are groomed to predestined constructs imagined by their parents' ideas and how this influences family harmony, business productivity, and possible transgenerational succession. It was found that mothers within family businesses tend to intertwine the achievements of their children with their own narrative, while fathers find themselves (or purposely place themselves) in a highly competitive "old bull/young bull" tension with their children. Playing favourites, intentionally causing competition and conflict, and grooming the wrong child for succession were identified as key characteristics of this form of the "gender agenda".

The second challenge facing the $\mathrm{CEmO}$ as an individual and as a concept relates to confidentiality, which was discussed exhaustively as a critical responsibility of the CEmO. It was suggested that CEmOs either intuitively possess or need to develop sound judgement in knowing what information to share, when, to whom, and for what purpose. In addition to this, CEmOs find effective ways of disclosing sensitive information in a manner that does not compromise the person who revealed it. In making sensitive judgements in relation to managing confidential information, CEmOs demonstrate that they act in accordance with an ethical framework that has been developed through collaborative dialogue, as the "family point of view" suggests. In calling on this ethical framework, CEmOs also uphold the family's values.

Inherent in confidentiality is trust and this idea returns to the work that provoked Pritchard (2011) to reflect on her own family's business, in which she identifies her mother as the CEmO. Pritchard cites Poza and Messer's (2001) "Chief Trust Officer" as one aspect of the role of the CEO's or founder's spouse. While "trust" is included in the tile of this role, it is built through one of the core activities of the $\mathrm{CEmO}$ role as outlined earlier, who recognised the CEmO's "major contribution to the family-owned business as providing the glue that keeps the family together through the predictable challenges families, especially families that work together face" (Poza and Messer 2001: 30). Without confidentiality and trust, there can be no harmony, and without harmony, productivity and potential cannot be realised and nothing of value to the business can be accomplished. This is the third challenge: achieving and maintaining family harmony.

It was agreed that CEmOs who master the "what" and "how" of the role are better placed to foster family harmony and business productivity. As mediators of harmony, CEmOs (in the main, as CEO spouses) tend to promote equality, communication, and cooperation (Wolper 2012). In doing so, they are natural peacemakers, effective in sibling management (Aronoff 1998; Lansberg 1995) and in bringing people together because of their deep knowledge of relationships (Barrett 2010). CEmOs care for "peace and harmony in the family and in the firm and... help avoid the appearance of conflicts between the relatives 
who work together in the firm" (Jimenez 2009: 55).

Nevertheless, a number of research participants cited examples of family-owned bus operations in which family members who are active in the business do not speak to or engage with each other. Without exploring the individual cases further, it was noted that these businesses are productive (to an extent), despite the disharmony within their respective families. The implications of such scenarios include compromised productivity due to a fractured workplace environment that affects staff morale and engagement; and compromised communication that may lead to ill-informed decision making and tensions within the family involving power, control, rumour, and speculation. This situation represents a challenge for any $\mathrm{CEmO}$ to navigate and manage.

The fourth challenge identified was the general attitude toward acknowledging and discussing "emotions" in the workplace, especially in traditionally male-orientated workplaces. One of the questions raised in the forum was: How can the CEmO concept be sold to a large, predominately male workforce whose average age is over 55 and who may be sceptical of the company's intention in introducing such a role (consolidated question from the focus group).

With CEmOs' leveraging and leading emotions in the business, research participants recognised the need for EI-as both a concept and an ability-to be embedded in organisational culture. Ingraining EI in a family business in a way that is palatable and appropriate was identified as the primary obstacle faced by the CEmO, although perhaps not by them alone. It was agreed that $\mathrm{EI}$ is not the domain of the CEmO solely, but should be a skill practised by all managers. One of the questions unable to be explored further during the focus group was that businesses could develop their supervisor's and manager's EI skills.

The interviewees toyed with the idea of engaging an external third party to help facilitate family harmony and business productivity when the $\mathrm{CEmO}$ is unable to cut through or requires assistance. This was identified as the fifth challenge facing the CEmO: At what point should an external party be engaged to help facilitate outcomes, obtain cut through, and possibly take on aspects of the CEmO's role?

While the benefits of an external party were acknowledged, especially in times of transition, consideration was given to what a small or micro family business would need to do to accept third-party non-family intervention, and how it would encourage all family members to perceive such support as valuable. In addition, deliberation over the skill set an external party would need to possess, the outcomes it would need to facilitate and the boundaries that would need to be established prior to commencing, and how a family business would afford such help.

Counter to this, Lyons and Rivers (2008) are vehemently against the $\mathrm{CEmO}$ role when a family business is transitioning or when it is faced with highly charged issues:

(W)e think that having the Chief Emotional Officer is one of the worst family business recommendations that we have seen. (Lyons and Rivers 2008: 3)

(T)he last thing a transitioning family needs is an increased dose of emotion especially when the emotion comes from someone who formally or informally, by self-acclamation or family election, takes on the role of Chief Emotional Officer! (Lyons and Rivers 2008: 1)

Challenges related to formalising the role of the CEmO emerged. This is the sixth challenge facing the CEmO: Whether or not to leave the $\mathrm{CEmO}$ as an implied and informal role rather than formalising and publically appointing someone to the role. Within the bus and coach industry, which has a predominantly male workforce, it was felt that formalising the role of $\mathrm{CEmO}$ would be problematic. This may be indicative of the "gender agenda" and the attitude toward emotions and EI in the workplace. Regarding whether a business should formalise the role or not, it was suggested that one way of addressing the possible 
barriers facing the role would be to establish a framework for how the role might work. However, it was resolved that this would be problematic, given that so much of what this role encompasses is tacit knowledge - an intuitive understanding of the family's dynamic and interactions among its members and with the business. As a result, it was agreed that there is no need to formalise the role; instead, the valuable contribution of the individual who carries out the implicit role should be recognised to enable the incumbent to embrace and enjoy the role, and to enable other company members to make use of the resource.

\section{The Three Foundation Competencies of the CEmO}

In considering the $\mathrm{CEmO}$ role, the outcomes they achieve, and the obstacles they face, it was discovered that there are perhaps three foundation competencies that CEmOs master. Success in effectively and efficiently facilitating better decisions while managing family harmony and ensuring business productivity during significant business transition is underpinned by these competencies:

(1) Facilitate harmony, the willingness and ability to deftly guide the family and the business through collaborative decision making, conflict, and transition;

(2) Drive productivity, by influencing improvements to business strategy, operations, leadership, and culture as the "go to" sounding board and the "glue" that holds everyone together;

(3) Focus decision making, by upholding and defending "the good", the values, norms, and traditions associated with the culture, operations, resources, and reputation of the family.

It was noted that EI was viewed as critical ability that spans all three competencies and is not exclusive or isolated to one competency, nor a competency of its own.

Through mastering these foundation competencies, it was discussed that the $\mathrm{CEmO}$ would be able to affect better, more contextualised outcomes, reduce family and workplace conflict, ensure equity and fairness in contribution and in "being heard" within the family, foster greater engagement with family and business stakeholders and generally improve communication both within the family and within the business.

\section{Further Research}

Now identified, further research would need to focus on refining the three competencies and give consideration to formal, professional development for a role that is often unstructured, intuitive, and unrecognised within the business. In considering professional development for the $\mathrm{CEmO}$, determining an appropriate model of learning will influence instructional design and delivery. In determining professional development for the $\mathrm{CEmO}$, research will also need to explore the necessity, impact, and process of formally appointing a CEmO in both family and non-family businesses alike. Key considerations could include:

(1) How would a company formally appoint a CEmO? Would the role be remunerated? What are the key functions, boundaries, and targets?

(2) If formalised, would the incumbent CEmO comfortably accept responsibility?

(3) What are the negative impacts of formally recognising a $\mathrm{CEmO}$ on business harmony, productivity, and decision making, and how could they be overcome?

\section{CONCLUSIONS}

This paper sought to identify the fundamental competencies and how they can be formally developed. Three foundation competencies were discovered: facilitate harmony, drive productive, and focus on decision making. Now identified, further research would need to focus on refining these competencies and give consideration to formal, 
professional development for a role that is often unstructured, intuitive, and unrecognised within the business. Further research needs to turn to professional development for the $\mathrm{CEmO}$, in regards to determining an appropriate model of learning, design, and delivery. In determining professional development for the $\mathrm{CEmO}$, research will also need to explore the necessity, impact, and process of formally appointing a CEmO in both family and non-family businesses alike.

The research findings reinforce the current view of the role and value of the $\mathrm{CEmO}$ within the literature. Defined, the CEmO is an individual who has not only mastered EI but also exhibits a mastery of the foundation competencies, used to maintain the nexus between family harmony and business productivity. The CEmO's abilities are intuitively accomplished and played out in the background, and often go unrecognised. In addition, challenges were identified that CEmOs would need to overcome as individuals, or that would need to be addressed at an organisational level.

The paper also offers a new perspective of the $\mathrm{CEmO}$ as a non-female, non-spouse, and non-family member. Our understanding of the CEmO now includes preliminary evidence that they exist in non-family firms, indicating that the ability to facilitate harmony, drive productivity, and informed decision making are highly valued in all organisations.

Specifically, it was asserted that the role of CEmO in family businesses is central to developing the "family point of view", resulting in better decisions made by the family for the family business. Informed decision making is of key concern to both family-owned and operated bus companies within the site of research, especially in the current "get big or get out" environment.

As academic and professional institutions worldwide continue the search for points of difference that positively affect various governance models, business sustainability and succession, professional development and business education, it is hoped that further concentration on the features and benefits of the CEmO in family businesses will ensue.

\section{Acknowledgements}

The authors would like to thank David Mead and Sean Copeland from Volvo and CMV for their continued vision and support for BAV's "Women on Board" series. Thanks also to Leah Waymark, Erica Nelson, and Pip Taylor for their participation as interviewees and to the participants in the focus group.

\section{References}

Aronoff, C. E. 1998. "Megatrends in Family Business." Family Business Review 11(3):181-185.

Australian Bureau of Statistics. 2013. Glossary 8155.0 Australian Industry. Retrieved March 10, 2014 (http://www.abs.gov.au/ausstats/abs@.nsf/Lookup/8155.0G lossary12011-12).

Barrett, M. 2010. "Women Leading Family Businesses." Family Business Wiki. Retrieved March 10, 2014 (http://familybusinesswiki.ning.com/profiles/blogs/womenleading-family).

Coalition Party. 2013. The Coalition's Policy for Small Business. Retrieved March 10, 2014 (http://lpaweb-static. s3.amazonaws.com/13-08-19\%20The $\% 20$ Coalition $\%$ E2\%8 0\%99s\%20Policy\%20for\%20Small\%20Business.pdf).

Cole, M. 1999. "Become the Leader Followers Want to Follow." Supervision 60(12):9-11.

Conley, C. 2011. "The Chief Emotions Officer." Huffington Post. Retrieved March 10, 2014 (http://www. huffingtonpost.com/chip-conley/the-chief-emotions-office_ b_849315.html).

Costin, G. P. 2002. "Legitimate Subjective Observation (LSO) and the Evaluation of Soft Skills in the Workplace." Presented at the National Training Framework-Training Partnerships and Regional Development Conference, May 2002, Albury Convention Centre and Performing Arts Centre.

Currie, G. and A. Delbosc. 2009. 2009 Bus Industry Survey. Retrieved March 10, 2014 (http://www.busvic.asn.au/ images/uploads/public/Vic_Bus_Industry_Survey_2009_-Monash.pdf).

Family Business Australia. 2013. Family Businesses in Australia-Different and Significant: Why They Shouldn't Be Overlooked. Parliamentary Joint Committee on Corporations and Financial Services, Senate Printing Unit, 
Parliament House, Canberra.

Freeman, R. E. 1994. "The Politics of Stakeholder Theory: Some Future Directions." Business Ethics Quarterly 4:409-421.

Fryer, D. 1991. "Qualitative Methods in Occupational Psychology: Reflections Upon Why They Are so Useful but so Little Used.” The Occupational Psychologist 14:3-6.

Gillis-Donovan, J. and C. Moynihan-Bradt. 1990. "The Power of Invisible Women in the Family Business." Family Business Review 3(2):153-167.

HjYunus, N. and C. N. Hassan. 2012. "The Importance of Emotional Intelligence and Soft Skills in the Workplace." Presented at the International Conference on Innovation Management and Technology Research (ICIMTR), May 21-22, Malacca, Malaysia.

Hoffman, J., M. Hoelscher, and R. Sorenson. 2006. “Achieving Sustained Competitive Advantage: A Family Capital Theory." Family Business Review 19(2):348-368.

Jimenez, R. M. 2009. "Research on Women in Family Firms: Current Status and Future Directions." Family Business Review 22(53):53-64.

LaChapelle, K. and L. Barnes. 1998. "The Trust Catalyst in Family-owned Businesses.” Family Business Review 11(1):1-17.

Lansberg, I. 1995. "The Power of the Chief Emotional Officer." Family Business Magazine, Spring, pp. 28-30. Retrieved March 10, 2014 (https://www.lgassoc.com/Articles/ customer-files/12-SPRING95.pdf).

Lyons, M. and W. Rivers. 2008. "Does Your Business Need a 'Chief Emotional Officer'?" Family Business Advisor. Retrieved March 10, 2014 (http://www.familybusiness institute.com/images/fbi/resources/articles/09-02-08_does_ your_business_need_a_ceo.pdf).

Mayer, J. D. and P. Salovey. 1989. "Emotional Intelligence." Imagination, Cognition and Personality 9(3):185-211.

Mayer, L. G. 2008. “'Chief Emotional Officer' Role Involves Daunting Challenges." Family Business, Summer, pp. 30-36.

Meng-Yun, W., X. Yan, and L. Wen. 2010. "Chief Emotional Officer and Succession of Family Enterprises: A Review Based on Relational Governance." Management Science and Engineering, November, pp. 564-569.

National Institute of Economic and Industry Research. 2010. The Economic Contribution of the Bus Industry to Victoria by Local Government Area: Part One-The Operational Contribution. Retrieved March 10, 2014 (http://www. busvic.asn.au/images/uploads/public/NIEIR_2010_Econom ic_contribution_of_bus_in_Vic_part_1_final_report.pdf).

Poza, E. J. and T. Messer. 2001. "Spousal Leadership and Continuity in the Family Firm." Family Business Review 14(25):25-36.

Pritchard, A. 2011. "Putting Family in Family Business: The Role of the Chief Emotional Officer." Pp. 178-185 in Family Business and Social Capital, edited by R. L. Sorenson. Cheltenham, UK: Elgar.

Reynolds, A. 2005. "Best Behavior." Supply Management 10(7):35.

Sorenson, L. S. and J. L. Ward. 1989. "The Role of 'Mom'." Nation's Business 77(8):40.

Sorenson, R. L. 1999. "Conflict Strategies Used by Successful Family Businesses." Family Business Review 12(4):325-339.

- 2013. "How Moral and Social Values Become Embedded in Family Firms." Journal of Management, Spirituality \& Religion 10(2):116-137.

Sorenson, R., K. Goodpaster, P. Hedberg, and A. Yu. 2009. "The Family Point of View, Family Social Capital, and Firm Performance: An Exploratory Test." Family Business Review 22(3):239-253.

Wolper, B. E. 2012. "Chief Emotional Officers Set the Tone in Family Business.” Columbus CEO, September. Retrieved March 10, 2014 (http://www.columbusceo.com/content/ stories/2012/09/chief-emotional-officers-set-the-tone-in-fa mily-business.html).

\section{Bios}

Christopher Lowe, M.B.A. (C.S.U., 2006), Ph.D. candidate at Monash Sustainability Institute, Melbourne, Australia, executive director, Bus Association Victoria Inc. (Australia); research fields: social externalities, governance, family businesses, bus industry, and voluntary professional associations. Julia Evans, BA, BEd\&T, MEd, DEd, independent scholar and director of Australian consulting firm Corven, Australia; research fields: educational philosophy and theory, adult learning, workplace education and training and competency based training. 